\title{
An aqueous pomegranate seed extract ameliorates oxidative stress of human hepatoma HepG2 cells
}

\author{
Marta Navarro, a Miryam Amigo-Benavent, a Marta Mesias, a Gema Baeza,a \\ Vural Gökmen,b Laura Bravoa and Francisco J. Moralesa*
}

* Correspondence to: Francisco J Morales, Institute of Food Science, Technology and Nutrition (ICTAN-CSIC), E-28040 Madrid, Spain. E-mail: fjmorales@ictan.csic.es

a Institute of Food Science, Technology and Nutrition, ICTAN-CSIC, E-28040, Madrid, Spain

b DepartmentofFoodEngineering,HacettepeUniversity,Beytepe,Ankara,Turkey

(wileyonlinelibrary.com) DOI 10.1002/jsfa.6469

\begin{abstract}
BACKGROUND: Aqueous pomegranate seed extract (PSE), a by-product of the pomegranate juice industry, was recently identified as a potential antiglycative ingredient. Ellagic acid was proposed as the major polyphenol responsible for the antiglycative activity as exerted in in vitro models. However, there is no information on safety aspects of this extract in biological systems before its application as ingredient. The cytotoxicity of PSE $(I-100 \mu g \mathrm{~mL}-I)$ was evaluated by determining its effect on cell viability and redox status of cultured HepG2 cells. The protective effect of the PSE against oxidative stress induced by tert-butyl hydroperoxide $(t-\mathrm{BOOH})$ was also investigated.

RESULTS: No changes in cell integrity or intrinsic antioxidant status resulted from a direct treatment with aqueous PSE, even at high dosage. In addition, reactive oxygen species (ROS) induced by $t-\mathrm{BOOH}$ were reduced by $21 \%$ when cells were pretreated with $100 \mu \mathrm{g} \mathrm{mL}-I$ of aqueous PSE at $180 \mathrm{~min}$. The range of concentrations investigated was effective in decreasing the ROS formation but not in a dose-dependent manner.

CONCLUSION: Aqueous pomegranate seed extract enhances human hepatoma cells integrity and resistance to cope with a stressful situation at concentration up to $100 \mu \mathrm{gmL}-1$
\end{abstract}

\section{INTRODUCTION}

Punica granatum (pomegranates), belonging to the Punicacea family, has a remarkable content in polyphenols, particularly hydrolysable tannins (ellagitannins and gallotannins) and anthocyanins (delphinidin, cyanidin and pelargonidin). Based on its high content of antioxidants, consumption of pomegranate as fruits or juice has been largely related to chemopreventive and anti-inflammatory effects.I Hence several pomegranate containing products have been marketed around the world in recent years. However, pomegranate fruits contain considerable amounts of seeds (about $20 \%$ $w / w)$, which are an important byproduct in the elaboration of the pomegranate juice. Recently, our group identified a significant antiglycative activity of an aqueous pomegranate seeds extract (PSE). PSE showed in vitro inhibitory effect of the formation of advanced glycation end-products (AGEs) through two mechanisms: (I) preventing glycation and (2) scavenging methylglyoxal, a potent AGE precursor. 2

AGEs have received great attention because of their association with the ageing process 3 and related chronic diseases such as diabetes mellitus and its complications4 Alzheimer's disease 5 or atherosclerosis. 6 For this reason, many investigations have been driven by the search for inhibitors of AGE formation. Initial investigations focused on synthetic AGE inhibitors such as aminoguanidine,7 and other inhibitors (carnosine5 or pyridoxamine7). However, it has been demonstrated that aminoguanidine can exert serious side effects in animal models. In fact, aminoguanidine can inhibit diamine oxidase and nitric oxide synthase enzymes involved in vascular and inflammatory processes. 8 In this sense, efforts have been devoted to the study of natural substances.7 Plant by-products have been considered as a good alternative to present compounds with antiglycative and antioxidant capacity. These phytochemicals are mostly phenolic compounds, being the most widely investigated ellagic acid, chlorogenic acid, gallic acid, ferulic acid and caffeic acid.9-12 Several studies have shown that pomegranate fruit has a positive effect on the prevention and treatment of the diseases mentioned previously. Again, the high content of phenolic compounds plays a pivotal role on the biological properties of the pomegranate, although each compound contributes in a different way. 13 On the other hand, the fruit part, variety, extraction method or industrialisation process influence the content of these biochemical compounds.I In this regard, 
research has been carried out with pomegranate juice or peel, while studies with seeds have been focused on the beneficial effects of certain polyphenols, polyunsaturated fatty acids, conjugated linolenic acid, punicic acid and tocopherols, 14 all present in the seed oil. Nevertheless, there are few studies on the potential genotoxicity of whole pomegranate hydroalcoholic extracts tested both in vitro and in vivo. 15 Basic toxicological information is required before further suggestion of its application as an ingredient in foods or pharmacological preparations.

The aim of this study was to investigate the toxicity, in terms of cell injury, and cellular redox status potential change of a human hepatoma cell line (HepG2) after treatment with different concentrations of PSE. The effect of PSE on cell viability and oxidative stress induced by tert-butyl hydroperoxide $(t-\mathrm{BOOH})$ was evaluated.

\section{MATERIALS AND METHODS}

\section{Materials}

Pomegranate seeds were provided by TIKTA (Ankara, Turkey). HumanhepatomaHepG2cells were supplied by Dr Paloma Mart'ın-Sanz (Instituto de Bioqu'ımica, CSIC, Madrid, Spain). Dubelcco's modified Eagle's medium (DMEM-FI2) and fetal bovine serum (FBS) were purchased from Biowhitaker Europe (Innogenetics, Madrid, Spain). Gentamicin, penicillin, streptomycin, $t-\mathrm{BOOH}$, crystal violet, nicotine adenine dinucleotide reduced form (NADH) and Tris were from Sigma Chemical (Madrid, Spain). Sodium dodecyl sulfate salt, dimethyl sulfoxide (DMSO) and pyruvate were obtained from Panreac Quimica (Barcelona, Spain). The fluorescent probe 2_,7_-dichlorofluorescein diacetate (DCFHDA) was from Molecular Probes (Eugene, OR, USA) and cell culture dishes were acquired from Falcon (Cajal, Madrid, Spain). All other chemicals and reagents were of analytical grade.

\section{Preparation of seed extracts}

A portion $(500 \mathrm{mg})$ of ground pomegranate seeds previously characterised 2 was extracted in water $(25 \mathrm{~mL}$, twice) by means of agitation for $10 \mathrm{~min}$ at $50{ }^{\circ} \mathrm{C}$. Supernatants were pooled, centrifuged $\left(1400 \times \mathrm{g}\right.$ for $10 \mathrm{~min}$ at $\left.4{ }^{\circ} \mathrm{C}\right)$ and lyophilised. The extract thus obtained is rich in phenolic compounds, mostly gallic and ellagic acids, as reported elsewhere. 2

\section{Cell culture and treatment with pomegranate seed extracts}

HepG2 cells were grown in DMEM-FI2 medium, supplemented with $2.5 \%$ FBS and $50 \mathrm{mg} \mathrm{L}-\mathrm{I}$ of gentamicin, penicillin and streptomycin antibiotics. Cells were incubated in humidified atmosphere of $5 \% \mathrm{CO} 2$ at $37 \circ \mathrm{C}$. Under these conditions, two sets of experiments were designed for this study: (I) experiments of direct treatment of cells with PSE for $20 \mathrm{~h}$ to test for an effect of the tested compounds dissolved in FBS-free medium, since FBS might interfere in the performance of the assays and alter the results; 16 and (2) experiments of pretreatment of cells with PSE $20 \mathrm{~h}$ [cytotoxicity and reactive oxygen species (ROS) experiments] before submitting cells to an oxidative stress induced by $t$ $\mathrm{BOOH}(200 \mu \mathrm{mol} \mathrm{L}-\mathrm{I}, 3 \mathrm{~h})$ to test for a protective effect.

\section{Cell viability assay}

The viability ofHepG2 cells was determined using the crystal violet assay. 17 Cells were plated in 96-well plates with a density of 104 cells per well. Then, these were grown for $20 \mathrm{~h}$ with different concentrations of tested extracts $(I-100$ $\mu \mathrm{g} \mathrm{m}-\mathrm{I})$, washed with PBS and in cubated with $50 \mu \mathrm{L}$ of crystal violet $(0.2 \%$ in $2 \%$ ethanol) for 20 min. Plates were rinsed with water and dried twice. After adding $100 \mu \mathrm{L}$ of $1 \%$ sodium dodecyl sulfate, the absorbance was measured at $570 \mathrm{~nm}$ using a SynergyTM HT-multimode microplate spectrophotometer (Biotek Instruments, Inc, Winooski, VT, USA). Results are expressed as percentage of cell viability regarding viable untreated cells.

\section{Cytotoxicity assay}

Cell cytotoxicity was determined following the lactate dehydrogenase leakage (LDH) method. 18 Cells were plated at a density of $1.5 \times 106$ cells per plate in $60-\mathrm{mm}$ diameter plates and pretreated with different concentrations of pomegranate extract $(\mathrm{I}-100 \mu \mathrm{g} \mathrm{mL}-\mathrm{I})$ for $20 \mathrm{~h}$ in FBS-free medium. After that, culture medium was collected and the cells scraped in phosphate-buffered saline (PBS). Cells were sonicated to breakdown the cell membrane and release the total amount of LDH. Then, they were centrifuged $(1000 \times \mathrm{g}$, $15 \mathrm{~min}$ ) and the supernatant was collected. LDH was determined in culture medium and cell lysates, mixing with $5 \mathrm{mmol} L-I$ pyruvate, $0.35 \mathrm{mmol}$ L-I NADH and $84 \mathrm{mmol}$ L-I Tris. LDH leakage was estimated as the ratio between the LDH activity in the culture medium and total LDH cell 
content. In parallel, to evaluate the protection of PSE against a cytotoxic agent HepG2 cells were submitted to the procedure described above but, in this case, $t-\mathrm{BOOH}(200 \mu \mathrm{mol} \mathrm{L}-\mathrm{I})$ was added $3 \mathrm{~h}$ before the measurement.

\section{Determination of reactive oxygen species}

The dichlorofluorescein (DCFH) assay was used to quantify cellular ROS as a marker of the extent of cellular oxidativestress. 19 Cells were plated at a cell density of $2 \times 105$ cells perwell in 24-well plates and changed to FBS-free medium the day after. In direct treatment experiments, $10 \mu \mathrm{L}$ of DCFH (I0 mmol L-I in DMSO) were added to the wells and incubated at $37 \circ \mathrm{C}$ for $30 \mathrm{~min}$. Then, cells were washed twice with PBS and $0.5 \mathrm{~mL}$ of PSE dissolved in FBS-free medium ( $1-100 \mu g m L-I)$ were incorporated into thewells. Plates were immediately measured (time 0 ) using a microplate reader (SynergyTM HT-multimode microplate spectrophotometer) at an excitation/emission wavelength of $485 / 530 \mathrm{~nm}$. This method is based on the DCFH probe oxidation, by intracellular oxidants or $t-B O O H$, to DCF which emit fluorescence. ROS were determined by quantifying fluorescence at different times $(0,60,120$ and $180 \mathrm{~min})$. In protection experiments, cells were pre-incubated with $500 \mu \mathrm{L}$ of the PSE $(I-100 \mu g m L-I)$ for $20 \mathrm{~h}$. After that, $10 \mu \mathrm{L}$ of DCFH ( $10 \mathrm{mmol} L-I$ in DMSO) were added to the wells and incubated at $37 \circ \mathrm{C}$ for $30 \mathrm{~min}$. Then, cells were washed twice with PBS and $500 \mu \mathrm{L}$ of $t-\mathrm{BOOH}$ in FBS-free medium added. Control samples without $t$-BOOH were used as negative control. Results are expressed as fluorescence units.

\section{Statistical analysis}

Statistical analysis of data was performed using the Statgraphics Centurion XV Statistical program (Herndon, VA, USA). Data were tested for homogeneity of variances by using Levene's test. Analysis of variance was performed using ANOVA procedures followed by a Bonferroni test or Tamhane test when the variances were homogeneous or nonhomogeneous, respectively. Differences were considered significant at $P<0.05$. Data from three independent assays were expressed as the mean value \pm SD.

\section{RESULTS AND DISCUSSION}

After our previous study on the antiglycative and antioxidant capacity of PSE, 2 a question concerning safety issues of the PSE arose. Therefore, potential toxicity of PSE in terms of cell viability and effects on the general oxidative status was assessed in a human cell line. Since liver is the major location for xenobiotic metabolism, research on xenobiotics should be focused first on liver cells. HepG2 cells are a transformed cell line, which is well differentiated and characterised. In addition, HepG2 is a reliable cell model that responds to different test conditions. 18 Several studies have employed this cell line to evaluate the toxicity or protective effects of phenolic compounds against oxidative stress induced by $t$ BOOH.|9-2I

After selecting HepG2 cells as an appropriate model, the crystal violet assay was used to determine potential effects of

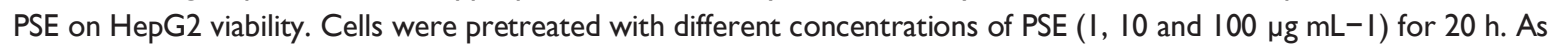
shown in Table I, reduction of cell viability determined as the relative density of adherent cells was not observed. Cell viability remained unchanged even at high concentrations of PSE (I00 $\mu \mathrm{g} \mathrm{mL}-\mathrm{I})$, which represents a high dose of this natural ingredient. LDH leakage from the cell cytosol to the culture medium was used as an indicator of cytotoxicity, and generally as an indicator of cell integrity. LDH leakage is estimated from the ratio between the LDH activity in the culture medium and the whole cell content. A range of PSE doses between I and $100 \mu \mathrm{g} \mathrm{mL}-\mathrm{I}$ was tested for a period of $20 \mathrm{~h}$ for their potential deleterious effect on HepG2 cells, as depicted in Fig. I (empty bar). Treatment with PSE significantly decreased LDH leakage as compared with untreated control cells. However, a dose-dependent effect was not observed at the concentrations tested $(I, 10$ and $100 \mu g \mathrm{~mL}-\mathrm{I})$ since results only ranged from $9.7 \%$ to $9.2 \% \mathrm{LDH}$ activity in the culture medium after $20 \mathrm{~h}$ for PSE concentrations from I to $100 \mu \mathrm{g} \mathrm{mL}-\mathrm{I}$. These results confirm the lack of cytotoxicity of PSE on HepG2 cells, even at high concentrations.

The protective effect of PSE against a cytotoxic inductor agent such as $t-\mathrm{BOOH}$ was also evaluated. It is known that decomposition of $t-\mathrm{BOOH}$ accelerates lipid peroxidation chain reactions, depletion of cell glutathione, and induction of cell toxicity by damage to DNA and apoptosis. 18 Cells were pretreated with different concentrations of PSE (I, I0 and $100 \mu \mathrm{g} \mathrm{mL}-\mathrm{I})$ for $20 \mathrm{~h}$ and then treated with $t-\mathrm{BOOH}$. A batch of cells not submitted to PSE was treated with 200 $\mu \mathrm{mol} \mathrm{L}-\mathrm{I} t$-BOOH for $3 \mathrm{~h}$ as a positive control for severe cell damage conditions. As depicted in Fig. I (solid bar), PSE efficiently prevented LDH leakage at concentrations of 10 and $100 \mu \mathrm{g} \mathrm{mL}-\mathrm{I}$ as compared with the control cells without 
pretreatment with PSE. A $50.6 \%$ of LDH leakage was obtained in control cells whereas in cells pretreated with PSE toxicity was significantly decreased to 37.3 and $34.9 \%$ of LDH leakage at the concentrations of 10 and $100 \mu g m L-I$, respectively. However, this protection was not statistically significant at the concentration of I $\mu g m L-I$.

The DCFH assay was used to determine intracellular ROS generation by measuring the fluorescence emitted by DCF after oxidation of DCFH. ROS generation is an important marker of the cell status since it causes damage to cellular components impairing or altering their metabolic functions. Figure 2 shows that PSE was effective in decreasing the formation of intracellular ROS, but its effectiveness varies with the time of exposure and the concentration of the extract. It is important to notice that direct application of PSE on HepG2 cells did not promote intracellular ROS formation at any concentration or time tested. The rate of ROS formation after 60 min of exposure was significantly reduced to $87.1,86.4$, and $84.9 \%$ for I, 10 and $100 \mu \mathrm{gL}-\mathrm{I}$, respectively. Nevertheless, effective protection was not observed for the highest concentration of PSE tested at the longest time of exposure. On the other hand, PSE concentration at I and $10 \mu \mathrm{g} \mathrm{mL}-\mathrm{I}$ for $180 \mathrm{~min}$ significantly reduced the generation of intracellular ROS. These results confirm that PSE, even at the highest rate of dosage, did not induce an oxidative damage into the cell model. In a next assay, cells were treated with $t-\mathrm{BOOH}$ as a chemical compound that induces oxidative stress. $t-\mathrm{BOOH}$ can decompose to other alkoxyl and peroxyl radicals in a reaction that generates ROS. 18 Figure 3 shows that PSE significantly decreased the ROS formation for all the concentrations tested as compared with untreated $t-\mathrm{BOOH}$ control. Although a doseresponse effect was not observed, the formation of ROS was significantly decreased with the time of exposure (79.I, 76.9 and $79.3 \%$ were achieved for I, 10 and $100 \mu \mathrm{gL}-\mathrm{I}$ at $180 \mathrm{~min}$, as compared with $100 \%$ of $t-\mathrm{BOOH})$. These results confirm the protective effect of PSE against an oxidative insult on $\mathrm{HeG} 2$ cell.

Various studies have shown that pomegranate is a fruit with anti-ageing, anti-atherosclerosis and anti-inflammatory effects, with potential protective effect against other cardiovascular diseases and neurodegeration.22-24 These effects are likely due to its content of bioactive compounds such as phenolics acids, flavonoids, punicalagin and ellagitannins.23,25 Extraction of the former bioactive compounds is strongly related to the extraction solvent used. Thus a methanolic extract of pomegranate peel presents higher antioxidant activity and phenolic content than does an aqueous extract and other parts of pomegranate, such as seed or leaf.26 In the present study, the seed coat was chosen as a byproduct and water was used for extraction as a cost effective and environmentally compatible approach 27 that was safer than if nonpolar solvents were used. Under these conditions, the hydrophilic compounds with antioxidant and antiglycative activities, such as gallic acid, ellagic acid and other phenolic compounds, were efficiently extracted.2,28 Although methanol or ethanol have been largely used as extraction solvents pomegranate, 15,28,29 aqueous extracts of tropical plants (roselle, spring onion, sweet potato, wild lime, or tapioca among other plants) have been proposed as a source of functional ingredients.30 A number of researchers have stressed the need to study the possible toxicity of non-edible parts of pomegranate since few studies have shown a certain toxicity of whole fruit extracts both in in vivo and in vitro assays. S'anchez-Lamar et al. 15 reported that a hydroalcoholic pomegranate fruit extract could be genotoxic at various expression levels. According to Vidal et al.29 amounts over $0.2 \mathrm{mg}$ of pomegranate hydroalcoholic extract produced embryotoxicity. In addition, other authors also suggested that roots and barks from pomegranate presented toxic effects probably due to their alkaloids, tannins or flavonoids. 15 Nevertheless, these toxic effects have been observed at higher concentrations than those that are effective as antivirals or are intended for the treatment of respiratory diseases. On the contrary, studies performed with aqueous extracts have not shown toxic effects, although there is some controversy. Settheetham and Ishida3I reported that aqueous pomegranate peel extract induced apoptosis in human cells in in vitro assays. In the present study the safety of the PSE was evaluated employing HepG2 as a cellular model. Cells were pretreated with a range of PSE concentrations ( $I$ to $100 \mu \mathrm{gmL}-\mathrm{I}$ ) and it was observed that extracts did not decrease cell viability or produce a cytotoxic effect. Moreover, treatment with PSE showed a significant protection of cells against $t-\mathrm{BOOH}$ toxicity. Aqueous extracts would be easier to obtain in a juice or seed infusion compared with non-aqueous extracts so it has more advantages for the consumer.

Hiraganahalli et al.32 stated that pomegranate peel extract exerts a significant liver protective effect against $t-\mathrm{BOOH}$ toxicity and this might be correlated with a radical scavenging effect. Likewise, other studies have shown a hepatoprotective capacity of pomegranate peel extract against $\mathrm{CCl} 4$, a cytotoxic agent studied as a liver toxicant. Studies in vivo have shown a protective effect of pomegranate in liver cells by recovery the normal hepatic architecture. 28 In the present study, intracellular ROS production was reduced after undergoing oxidative injury with $t$ - $\mathrm{BOOH}$. The literature 
points out that pomegranate's phenolic content may be related to its antioxidant capacity, which is higher in peels and flowers than in leaves and seeds.33 Nevertheless, at high concentrations $(100 \mu \mathrm{gL}-\mathrm{I})$ the effect was significantly reduced regarding the time of exposure compared with lower concentrations of $\mathrm{I}$ and $10 \mu \mathrm{gL}-\mathrm{I}$. This behaviour could be explained by dual antioxidant and pro-oxidant activities of phenolic compounds such as gallic or ellagic acid,34 which are the most abundant phenolic compounds in PSE.2,35 Recent studies have reported several biological functions of ellagic acid, highlighting its anti-inflammatory, antioxidant and antimutagenic activities. In addition, ellagic acid can also exert a hepatoprotective effect against $\mathrm{CCl} 4$ both in vitro and in vivo, contributing to the recovery of cellular antioxidants.36 In a similar way, gallic acid may exhibit antimutagenicity and a significant antioxidant effect. Yeh et al.37,38 revealed that this phenolic acid is a potent inducer of phenolsulfotransferase which shows a cytoprotector effect against oxidative injury. However, gallic and ellagic acids may behave as pro-oxidants like other phenolic compounds, although the mechanism of action has not been elucidated yet.34 Gallic acid has shown a slight metal chelating and high electron donating capacities, which could explain its pro-oxidant effects at high concentrations. Its ability to induce cytotoxicity and apoptosis in certain cell lines strengthens this dual activity.II On the other hand, the possibility that phenolic compounds may have antagonistic or synergistic effects with themselves or with other compounds can influence this duality. 2

\section{CONCLUSION}

The studied aqueous pomegranate seed extract with antiglycative properties did not exert toxicity on HepG2 cell as a human hepatic cell model even at high exposure levels. Hepatic cells shouldmetabolise PSE without detrimental effects on cell viability. Although literature describes that delphinidin, cyanidin and pelargonidin present in hydroalcoholic pomegranate extracts could exert cytotoxic effects,39 the aqueous extract investigated in this study showed a remarkable positive effect on the prevention and reduction of the oxidative stress of HepG2 cells. The protective effect was particularly accentuated at the lowest PSE concentrations assayed. Although in vivo studies are needed in a further step, this investigation points out that aqueous pomegranate extract with antiglycative properties can be safely used, in terms of cell toxicity and protection against oxidative stress, as an ingredient in foods and pharmacological preparations.

\section{ACKNOWLEDGEMENTS}

This work received grants from the Spanish Ministry of Science and Innovation under project NATURAGE (AGL20I0I7779) and AGRI464-ANALISYC-II (CAM). M. Navarro and M. Amigo-Benavent have contracts from the JAE program from CSIC, co-funded by the European Social Fund. G. Baeza has an FPI fellowship from MINECO. The Project Consolider Ingenio CSD2007-00063 is also acknowledged. 


\section{REFERENCES}

I Mena P, Giron'es-Vilaplana A, Moreno DA and Garc'ia-Viguera C, Pomegranate fruit for health promotion: Myths and realities. Funct Plant Sci Biotechnol 5:33-42 (20I I).

2 Mes' iasM, Navarro M, G“okmen $V$ andMorales FJ, Antiglycative effect of fruit and vegetable seed extracts: inhibition of AGE formation and carbonyl trapping abilities. J Sci Food Agric 93:2037-2044 (2013).

3 Luevano-Contreras C and Chapman-Novakofski K, Dietary advanced glycation end products and aging. Nutrition 2:1247-1265 (2010).

4 Delgado-Andrade C, Maillard reaction products: Some considerations on their health effects. Clin Chem LabMed 2:I-8 (20I3).

5 M"unch G, Thome J, Foley P, Schinzel R and Riederer P, Advanced glycation endproducts in ageing and Alzheimer's disease. Brain Res Rev 23:134-I43 (1997).

6 Vlassara H, Advanced glycation end-products and atherosclerosis. Ann Med 28:419-426 (1996).

7 Thornalley PJ, Use of aminoguanidine (Pimagedine) to prevent the formation of advanced glycation endproducts. ArchBiochemBiophys 4 19:3I-40 (2003).

8 Rahbar S and Figarola JL, Novel inhibitors of advanced glycation endproducts. Arch Biochem Biophys 4I 9:63-79 (2003).

9 Booth AA, Khalifah RG and Hudson BG, Thiamine pyrophosphate and pyridoxamine inhibit the formation of antigenic advanced glycation end-products: comparison with aminoguanidine. Biochem Biophys Res Commun 220:I I3-I I9 (I996).

10 Gugliucci A, Bastos DH, Schulze J andSouzaMF, Caffeic andchlorogenic acids in llex paraguariensis extracts are the main inhibitors of AGE generation by methylglyoxal in model proteins. Fitoterapia 80:339-344 (2009).

I I Wu JW, Hsieh CL, Wang HY and Chen HY, Inhibitory effects of guava (Psidium guajava L.) leaf extracts and its active compounds on the glycation process of protein. Food Chem I I 3:78-84 (2009).

I2 Silv 'an JM, Assar SH, Srey C, Del CastilloMDand Ames JM, Control of the Maillard reaction by ferulic acid. Food Chem I28:208-2I3 (20II).

13 SeeramNP,Berry fruits: Compositional elements, biochemical activities, and the impact of their intake on human health, performance and disease. J Agric Food Chem 56:627-629 (2008).

14 Jing P, Ye T, ShiH, Sheng Y, Slavin M, Gao B, et al.,Antioxidant properties and phytochemical composition of Chinagrown pomegranate seeds. Food Chem I32:1457-I464 (20I2).

I5 S'anchez-Lamar A, Fonseca G, Fuentes JL, Cozzi R, Cundari E, Fiore M, et al., Assessment of the genotoxic risk of Punica granatum L. (Punicaceae) whole fruit extracts. J Ethnopharmacol I I 5:4I6-422 (2008).

I6 Al'ia M, Mateos R, Ramos S, Lecumberri E, Bravo L and Goya L, Influence of quercetin and rutin on growth and antioxidant defense system of a human hepatoma cell line (HepG2). Eur J Nutr 45: 19-28 (2006).

17 Valdes F, MurilloMM,ValverdeAM,Herrera B, S'anchez A, Benito M, et al., Transforming growth factor-beta activates both pro-apoptotic and survival signals in fetal rat hepatocytes. Exp Cell Res 292:209-218 (2004).

I8 Al'ıa M, Ramos S, Mateos R, Bravo L and Goya L, Response of the antioxidant defense system to tert-butyl hydroperoxide and hydrogen peroxide in a human hepatoma cell line (HepG2). J Biochem Mol Toxicol I 9:I I 9-I 28 (2005).

19 Al'ıa M, Ramos S, Mateos R, Granado-Serrano AB, Bravo L and Goya L, Quercetin protects human hepatoma HepG2 against oxidative stress induced by tert-butyl hydroperoxide. Toxicol Appl Pharm 2 I 2: I I0-I I 8 (2006).

20 Granado-Serrano AB, Mart'in MA, Goya L, Bravo L and Ramos S, Time course regulation of survival pathways by epicatechin on HepG2 cells. J Nutr Biochem 20:I I5-124 (2009).

2I Le 'on-Gonz'alez AJ, Mateos R, Ramos S, Martin MA, Sarria B, Martin- Cordero C, et al., Chemo-protective activity and characterization of phenolic extracts from Corema album. Food Res Int 49:728-738 (20I2). 
22 Rajan S, Mahalakshmi S, Deepa VM, Sathaya K, Shajitha S and Thirunalasundari T, Antioxidant potentials of Punica granatum fruit rind extracts. Int J Pharm Pharm Sci 3:82-88 (20II).

23 Mena P, Garc'ia-Viguera C, Navarro-Rico J, Moreno DA, Bartual J, Saura D, et al., Phytochemical characterization for industrial use of pomegranate (Punica granatum L.) cultivars grown in Spain. J Sci Food Agric 9 I:I893-1906 (20I I).

24 Hollebeeck S, Winand J, H'erentM-F, During A, Leclercq J, Larondelle Y, et al., Anti-inflammatory effects of pomegranate (Punica granatum L.) husk ellagitannins in Caco-2 cells, an in vitro model of human intestine. Food Funct 3:875-885 (20I2).

25 Kokila NR, Chethan M, Gangadhara NS, Harsha R, Dinesha R and Thammanna SS, Antiglycation and antioxidant activity of polysaccharides isolated from fruit extract of pomegranate (Punica granatum). Pharmacologyonline I:82I-829 $(2010)$.

26 Tehranifar A, Selahavarzi Y, KharraziMand Bakhsh VJ.High potencial of agro-industrial by-products of pomegranate (Punica granatum L.) as the powerful antifungal and antioxidant substances. Ind Crop Prod 34:I523-I527 (20II).

27 Møller JKS,Madsen HL, Aaltonen T and Skibsted LH, Dittany (Origanum dictamnus) as a source of water-extractable antioxidants. FoodChem 64:215-219 (1999).

28 Murthy KNC, Jayaprakasha GK and Singh RP, Studies on antioxidant activity of pomegranate (Punica granatum) peel extract using in vivo models. J Agric Food Chem 50:4791-4795 (2002).

29 VidalA, Fallarero A, Pe na BR,MedinaME, Gra B, Rivera F, et al., Studieson the toxicity of Punica granatum L. (Punicaceae) whole fruit extracts. J Ethnopharmacol 89:295-300 (2003).

30 Wong SP, Leong LP and Koh JHW, Antioxidant activities of aqueous extracts of selected plants. Food Chem 99:775783 (2006).

3I SettheethamWand Ishida T, Study of genotoxic effects of antidiarrheal medicinal herbs on human cells in vitro. SE Asian J Trop Med 26:306-310 (1995).

32 Hiraganahalli BD, Chinampudur VC,Dethe S, Mundkinaieddu D, Pandre MK, Balachandran J, et al., Hepatoprotective and antioxidant activity of standardized herbal extracts. PharmacognMag 8: I I6-123 (2012).

33 Elfalleh W, Hannachi H, Tlili N, Yahia Y, Nasri N and Ferchichi A, Total phenolic contents and antioxidant activities of pomegranate peel, seed, leaf and flower. JMed Plants Res 6:4724-4730 (20I2).

34 Fukumoto LR and Mazza G, Assessing antioxidant and prooxidant activities of phenolic compounds. J Agric Food Chem 48:3597-3604 (2000).

35 Singh RP, Murthy KNC and Jayaprakasha GK, Studies on the antioxidant activity of pomegranate (Punica granatum) peel and seed extracts using in vitro models. J Agric Food Chem 50:8I-86 (2002).

36 Vattem DA and Shetty K, Biological functionality of ellagic acid: A review. J Food Biochem 29:234-266 (2005).

37 Yeh CT, Huang SM and Yen GC, Induction of phenolsulfotransferase expression by phenolic acids in human hepatoma HepG2 cells. J Agric Food Chem 53:4766-4773 (2005).

38 Yeh CT and Yen GC, Involvement of p38 MAPK and Nrf2 in phenolic acid induced P-form phenol sulfotransferase expression in human hepatoma HepG2 cells. Carcinogenesis 27:1008-1017 (2006).

39 Yeh CT and Yen GC, Induction of apoptosis by the anthocyanidins through regulation of Bcl-2 gene and activation of c-Jun N-terminal kinase cascade in hepatoma cells. J Agric Food Chem 53:1740-1749 (2005). 
Table I. Effect of pomegranate seed extract on HepG2 cells viability after treatment for $20 \mathrm{~h}$ Sample Cell viability (\%)

Control $100.00 \pm 6.86$

Seed extract $(\mu g \mathrm{~mL}-\mathrm{I})$

1

$04.92 \pm 10.05$

10

$105.85 \pm 11.21$

100

$103.22 \pm \mid 1.21$

Results are expressed as mean \pm SD $(n=4)$.

Significant differences were not observed $(P<0.05)$.

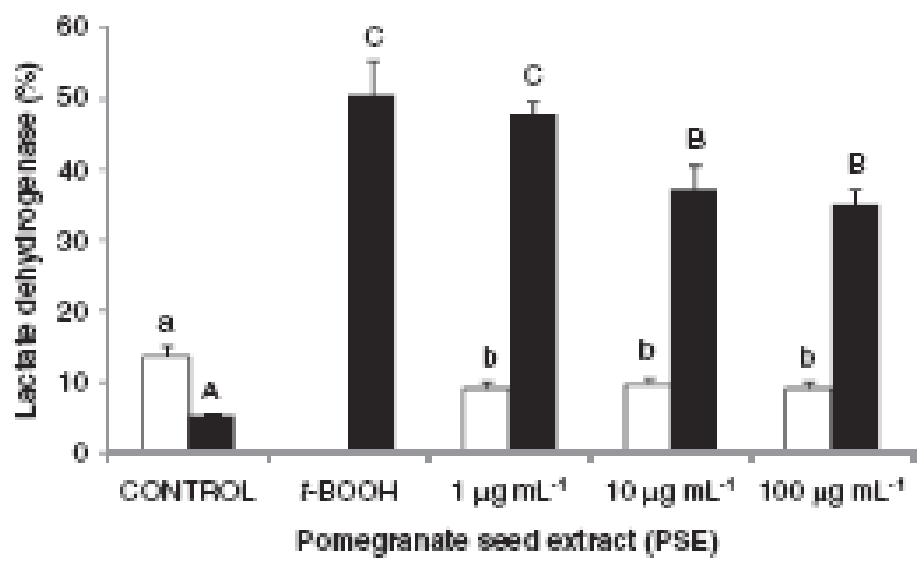

Figure I. Lactate dehydrogenase (LDH) leakage after treatment with pomegranate seed extract (PSE; I, 10 and I00 $\mu g$ $\mathrm{mL}-\mathrm{I})$ for $20 \mathrm{~h}$ (white bars) and after $t-\mathrm{BOOH}$ exposure for $3 \mathrm{~h}$ (black bars). Data show the mean \pm SD $(n=5)$. Different lower-case (white bars) and upper-case (black bars) letters indicate significant differences $(P<0.05)$.

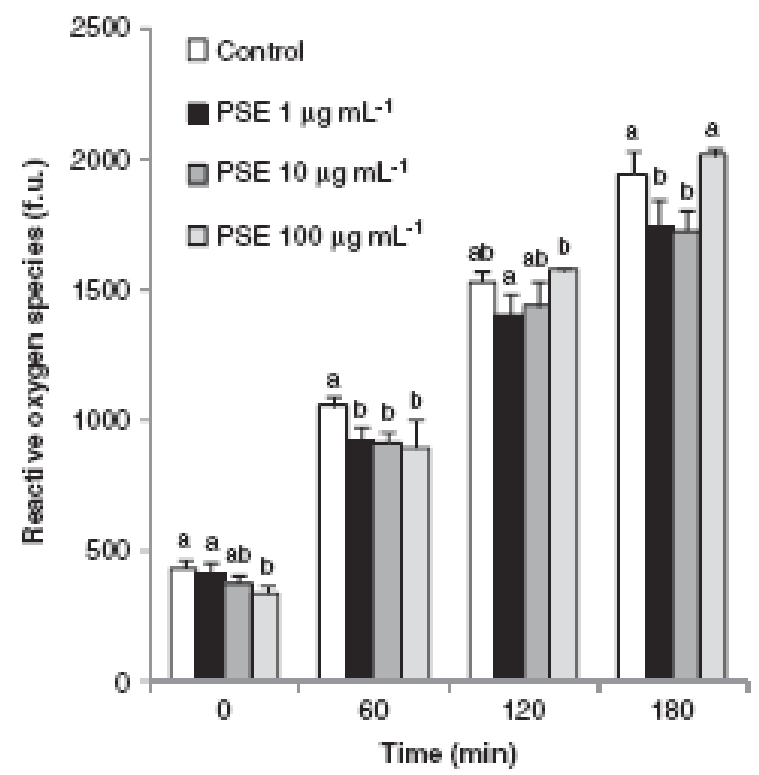

Figure 2. Intracellular generation of reactive oxygen species after treatment with pomegranate seed extract (PSE; I, I0 and $100 \mu \mathrm{g} \mathrm{mL}-\mathrm{I})$ at $0,60,120$ and $180 \mathrm{~min}$. Results are expressed as mean $\pm S D(n=4)$. Different letters denote significant differences $(P<0.05)$ within the same incubation time. f.u.: fluorescence units. 


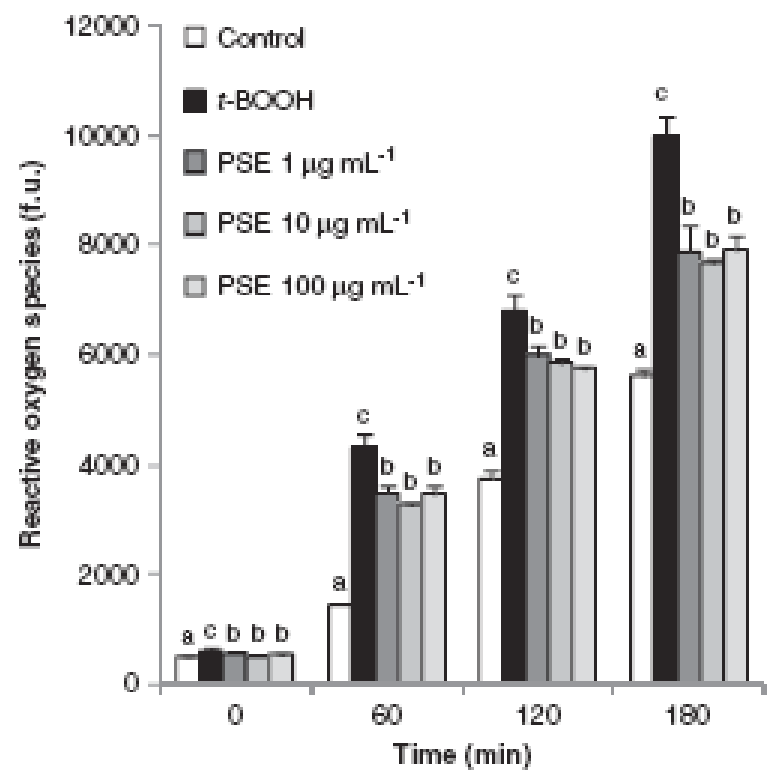

Figure3. Protective effect of pomegranate seed extract (PSE) pretreatment (I, 10 and $100 \mu g \mathrm{~mL}-\mathrm{I})$ for $20 \mathrm{~h}$ against oxidative stress induced by tertbutyl hydroperoxide $(t-\mathrm{BOOH})$ after $0,60,120$ and 180 min of exposure. Data show the mean \pm SD $(n=4)$. Different letters denote significant differences $(P<0.05)$. f.u.: fluorescence units. 